\title{
Prevalence of Maternal Mortality in West Africa: A Systematic Review
}

\author{
Kermue Vasco Jarnda ${ }^{1}$, Garmai Prosperity Roberts ${ }^{2}$, Williams Olokoro ${ }^{{ }^{*}}$ \\ ${ }^{I}$ Department of Maternal and Child Health, Xiangya School of Public Health, Central South University, \\ Changsha, Hunan, P.R. China \\ ${ }^{2}$ Department of Nursing, Columbia Union College of Health and Sciences, Adventist University of West Africa, \\ Advent Hill, Margibi County, Republic of Liberia, West Africa.
}

*Corresponding Author: Williams Olokoro, Department of Nursing, University of Ghana, Email: williamsol okoro@gmail.com

\begin{abstract}
Introduction: Maternal mortality is defined as the death of a woman during the course of her pregnancy, delivery or within 42 days of termination of pregnancy/100 000 live births. Maternal mortality is widely recognised as a marker of global inequality as it reflects access to care and is an important indicator of a country's general health profile. This review was conducted to objectively investigate the prevalence of maternal mortality in Africa
\end{abstract}

Study Design: Cross- Sectional Study

Search Strategy: A prevalence systematic review was conducted of English language articles published from 1990 to 2020. International databases, including PubMed, Web of Science, EMBASE, Science Direct, and the Cochrane Library, were systematically searched. All identified Cross-sectional studies reporting the prevalence of maternal mortality in West African countries were included.

Selection Criteria: All papers were screened by title and abstract in order to determine their eligibility for inclusion in the review. Full-texts of all remaining papers were screened to determine their inclusion or exclusion from the review.

Data Collection \& Analysis: Data were extracted from eligible publications

Main Results: A total of 6,012 records were identified through electronic database searching and 13 studies involving 437,802 reproductive age females were included. A total of 8 countries from West African countries were included. The prevalence of maternal mortality in Western Africa is $2.08 \%$ with a $95 \%$ confidence interval (CI) of $(0.85 \%, 3.83 \%)$, Ghana has the least prevalence of maternal mortality, whereas Nigeria, Liberia, and Burkina Faso, have [2\%, (0.01, 0.04)], [9\%, (0.04, 0.16)], and [5\%, (0.01, 0.13)], respectively, representing slightly higher prevalence of maternal mortality than their counterparts but the heterogeneity was substantially high $\left(I^{2}=100 \%, p<0.001\right)$.

Conclusion: The main causes of maternal mortality among Western African women are broadly similar to those for North, South and East African women, although the findings suggest some heterogeneity between countries and regions. However there is evidence that the relative importance of specific causes may differ for this younger age group compared to women over the age of 20 years. In particular hypertensive conditions make up a larger share of maternal deaths among West African Women.

Keywords: Prevalence; Maternal Mortality \& West Africa (1990z-2020)

Abbreviations: DHS: Demographic Health Survey; HMR: Hospital Medical Records; MDC: Method of Data Collection; MMR: Maternal Mortality Ratio; NOS: Newcastle-Ottawa Scale; PBS: Population Base Survey; QAS: Quality assessment score; SQ: Structured Questionnaire; WHO: World Health Organization

\section{INTRODUCTION}

Maternal mortality rate is a key indicator of the health status of a population. In 2013, the World Health Organization (W.H.O.) defined maternal mortality as the death of a woman whereas pregnant or within 42 days of the end of

ARC Journal of Gynecology and Obstetrics pregnancy, independent of the term and location of pregnancy (uterine or additional uterine) from any cause related to or made more awful by the pregnancy or its management [1]. Accomplishing great maternal health requires quality regenerative health services and an 
arrangement of well-timed intercessions to guarantee a women's secure section to motherhood. Failure to supply these services comes about in hundreds of thousands of unnecessary deaths each year. Each year, about half a million women and young ladies unnecessarily die as a result of complications amid pregnancy or childbirth, and 99\% happen in developing countries. [2]. Each day, about 830 women die from preventable pregnancyrelated causes [3], to date, few nations are on track to meet Millennium Development Goal 5 (MDG 5), which points to a $75 \%$ diminishment in maternal mortality by 2015 [4]. The maternal mortality ratio (MMR) per 100000 live births is estimated to be 920 in Africa, 330 in Asia, and 10 in Europe [5] Up to 80\% of these maternal deaths are directly due to five complications: haemorrhage, sepsis, eclampsia, rupture of the uterus (obstructed labor) and complications of abortion. Although reliable information about the individual medical causes of maternal mortality is scarce, especially in sub-Saharan Africa, [6] haemorrhage during labor, delivery, and postpartum accounts for one-third of all obstetric deaths in the world and is the leading cause of maternal deaths in Africa (34\%) and Asia (31\%) [6]. The statistics are especially disturbing in sub-Saharan Africa, where the lifetime risk of dying from childbirth is 1 in 31 , as compared to 1 in 4,300 in industrialized countries. [7]. Experiencing death circumstances such as maternal death for a drawn-out period of time or numerous times is common in rural zones of developing countries, because of the common deficiency and the low quality of the assets accessible to supply maternity services. [8]. Although 2015 global and regional estimates of maternal mortality indicate a descending drift, aggregate statistics mask differences in each country's progress [9] while some Sub-Saharan African countries such as Rwanda and Cape Verde met the MDG 5, estimates of maternal mortality in Nigeria indicates slow progress [9]. In 2015, Nigeria contributed to 1 in 5 and 1 in 4 global and regional maternal deaths, respectively [9] Findings from the 2008 and 2013 Nigeria Demographic and Health Survey (DHS) revealed an increase in maternal mortality ratio (MMR) from 545 to 576 deaths per 100,000 live births [10] Based on these estimates, a Nigerian woman in her reproductive years has a 1 in the 22-lifetime risk of maternal death, compared to the average lifetime risk of 1 in 4900 and 1 in 180 for women in high and low-income countries, respectively [3] The prevalence of maternal death may be as a result of many inconveniences and measures which are not put in place to curb the situation. There are several dimensions to maternal mortality. Fundamentally, a woman's death during pregnancy or childbirth is not only a health issue but also a matter of social injustice [11] reflecting the failure of communities and government to promote safe motherhood as a human right [12] [13]. Maternal mortality also reflects disparities in socio-economic development. A study conducted in Nigeria reveals that delay in the management of pregnancy complications are key factors of maternal mortality in developing countries, SubSaharan African and South Asia account for about $87 \%$ of all maternal deaths. This study reported failure to seek medical treatment in time accounts for $40 \%$ of maternal death, whiles difficulties in transportation and delays after the woman had arrived in a hospital accounts for $20 \%$ and $40 \%$ respectively. [14] [15] The overwhelming majority of maternal deaths occur in developing countries [11]. Sub-Saharan Africa and South Asia account for about $87 \%$ of all maternal deaths [15]. The lifetime risk of maternal death in sub-Saharan Africa is 1 in 31 compared to 1 in 4,300 in developed regions [15]. The higher risk in developing countries reflects the limited quality of care and the provision of maternal health services. [16][17]. In sharp contrast, a sequel to improvements in obstetric care over the past decades, a pregnant woman in the United Kingdom is reported to face a less than 1 in 19,020 risks of dying from obstetric complications directly related to the pregnant state [18]. To respond to this challenge, the Millennium Development Goal 5 (MDG 5), which aims to improve maternal health was developed. The target is to reduce by three-quarters the MMR between 1990 and 2015 and achieve universal access to reproductive health care by 2015. A study by Hogan and colleagues, in 2010, found that there was a decrease in the global MMR estimates from 320 in 1990 to 251 in 2008 per 100000 live births [19] Even in the presence of this change, very few countries are on track to achieve MDG 5 [19] This stagnation calls for different innovations and strategies to tackle this global menace. A study by Thonneau et al., (2004) [4] carried out in twelve maternities in Benin, Ivory Coast and Senegal, found that hypertensive disorders and post-partum haemorrhage caused $29 \%$ and $15 \%$ respectively of maternal mortalities in these three African countries. These were the highest causes of maternal 
mortality among this group [20]. 2007- 2008 Interim Demographic and Health Survey (DHS) indicated that $95.8 \%$ of Rwandan women attended at least one ANC visit, but that only $45.2 \%$ delivered at health facilities [21]

Similar studies conducted in Nigeria also reveals MMR of 2,085 per 100,000 live births in the hospitals (range: $877-4,210$ per 100,000 births) although there were several covariates identified as increasing the odds for maternal mortality; however after adjustment for confounding, five factors remained significant which includes delivery in a secondary health facility as opposed to delivery in a tertiary hospital, non-booking for antenatal and delivery care, referral as an obstetric emergency from nonhospital sources of care, previous experience by women of early pregnancy complications, and grand multi-parity. [22]

Despite the recent global emphasis on investment in better maternal health and the universal recognition that haemorrhage is a major cause of maternal death, very little is known about the impact of ineffective services on maternal mortality. To the best of our knowledge, this is one of the first systematic review analysis of maternal deaths in referral facilities in West Africa. We believe the results would be useful in designing policies and programs at the national and subnational levels for improving the quality of obstetric care and the management of obstetric complications that lead to maternal deaths in West Africa

$\mathrm{We}$, therefore, performed this systematic review with the aim to provide evidence base report of the prevalence of maternal mortality in West African countries that will serve as tangible data for future researchers and for policymaking and implementation of strategies to reduce maternal mortality.

\subsection{Systematic Review Registration}

The protocol of this systematic review was registered at PROSPERO (record ID= CRD42020189306, July 2020)

\section{METHODS}

The Preferred Reporting Items for Systematic Reviews and Meta-Analyses (PRISMA) reporting guidelines and checklist have been used to report each stage of the systematic review methods and findings. The protocol for this systematic review has been registered in the PROSPERO database (CRD42020189306)

\subsection{Eligibility Criteria}

ARC Journal of Gynecology and Obstetrics
Two investigators (KVJ \& GPR) independently screened the selected studies using their titles and abstracts before retrieving full-text papers. We used specified criteria to further screen the full-text papers. Disagreements were discussed during a consensus meeting for final selection of studies to be included in the systematic review.

\subsection{Information Sources}

Cochrane Library; Embase; PubMed; Science Direct and Web of Knowledge

\subsection{Search Strategy}

The search was performed to primarily identify Cross-Sectional studies published from January 1st, 1990 to January 31st, 2020, that reported on the outcome of interest to the review. Five databases were searched to identify eligible articles for inclusion into the review (Cochrane Library: 45 results; Embase: 117 results; PubMed: 1,283 results; Science Direct: 4,286 results and Web of Knowledge: 281 results). The searches were undertaken from January 1990 to January 2020.

EndNote X9 was used for recording and organizing all relevant bibliographic citations for the review. The search strategy comprised terms relating to Prevalence; Maternal Mortality; West Africa. All terms were searched for in the All text, Title, and abstract fields. The Boolean operators AND, and OR were used, alongside truncation, phrase searching, and proximity operators. The search syntax was adapted for each database

\subsection{Search Outcomes}

A total of 6,012 articles were identified using electronic search engine and strategies. Of these, 1,080 were excluded during the evaluation of duplicate giving us 4,932 articles after removal of duplicated studies. The evaluation of full text $\&$ abstract screening resulted in the exclusion of a further 980 articles. Therefore, the full-text of 13 studies were retrieved for further assessment.

\subsection{Study Design}

The study adapted a Cross-Sectional study design.

\subsection{Inclusion Criteria}

- Design type-Cross-Sectional studies

- Study participants- Pregnant women

- Those articles published in English language

- Studies that reported on prevalence of 
maternal mortality

- Studies conducted in West Africa

\subsection{Exclusion Criteria}

- $\quad$ Full text not found

- Conference Abstracts

- We also excluded editorials, letters, commentaries, and Cases report Studies

- Did not report on outcome of interest.

\subsection{Data Extraction}

Two investigators performed data extraction independently (KVJ \& GPR) and the results were compared, minimizing the likelihood that errors would go un-notify. The data was extracted using a standard data extraction form. The following information were extracted from the selected studies: first author's name, year of publication, study design, sample size/study population, method of data collection, cases, prevalence of maternal mortality, and maternal mortality ratio.

\section{RESUlTS}

\subsection{Study Selection}

All papers were screened by title and abstract in order to determine their eligibility for inclusion in the review. Full-texts of all remaining papers were screened to determine their inclusion or exclusion from the review
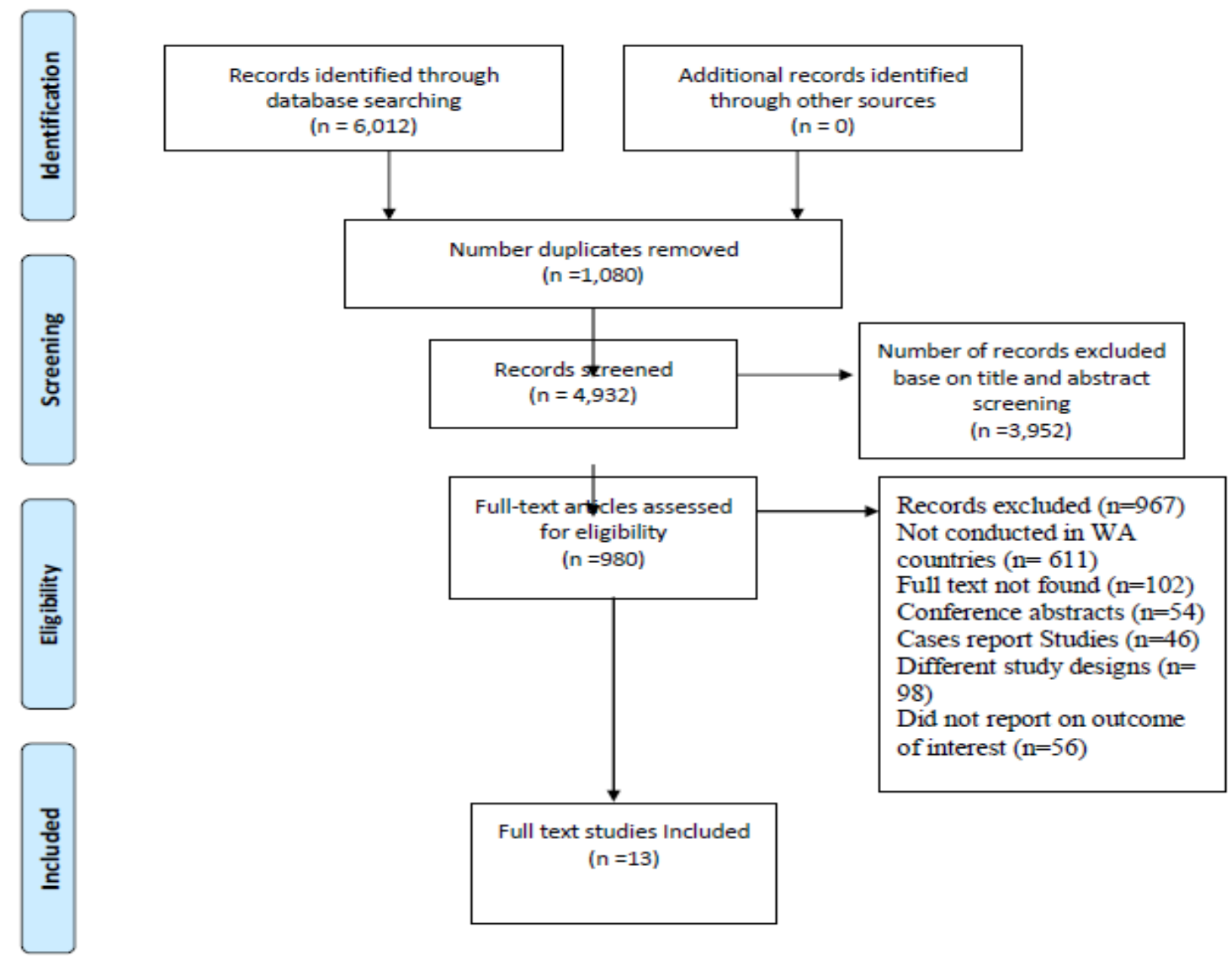

Figure1: Process of study selection for inclusion in this systematic review

\subsection{Characteristics of Included Studies}

A total of 6,012 records were identified through electronic database searching and a total of 5,999 studies were omitted through a systematic process. From the total omitted studies, 1,080 were duplicates, 3,952 were excluded based on title and abstract screening, 967 studies were excluded from a systematic review (Studies not conducted in West African countries: 611 studies; full text not found: 102 studies; conference abstracts: 54 studies; cases report
Studies: 46 studies; different study design: 98 studies; did not report on the outcome of interest: 56 studies). Finally, 13 studies involving 437,802 reproductive age females were included in this systematic review (see figure 1). The qualities of the 13 included studies were assessed using the New CastleOttawa Scale for cross-sectional studies (see Table 2). Ten of the included studies had a good methodological quality and three had fair methodological quality. 
The study with the smallest sample size by Lori, J.R. et'al 2010 included 148 subjects [23], while a multicounty study by Asamoah, B.O. et'al 2011 had the largest sample size of 226,209 subjects [24].The smallest prevalence of maternal mortality was estimated by Høj, L et'al $2002(0.8 \%)$ [25], while the largest prevalence was estimated by Lori, J.R.et' al 2010 (20\%) [23]. The 13 included studies were all conducted in West African countries (one study in Burkina Faso; two studies in the Gambia; one study in Ghana; one study in Guinea Bissau; two studies in Liberia; one in Mali \& Senegal; and five studies in Nigeria). All the thirteen included studies used a cross-sectional design.

\subsection{Quality of Included Studies}

We evaluated the quality of selected studies by a modified version of the Newcastle Ottawa Scale (NOS) [26] to appropriately assess the quality of

Table1: Search terms and search strategy per database
13 cross-sectional studies. As recommended by the NOS scale, we evaluated the included studies by the following domains: first author; sample size and non-respondents; second, ascertainment of the exposure; comparability of subjects \& control of confounding factors; third, assessment of the outcome and statistical quality. A grade of one to ten (1-10) stars was used to assess the methodological quality of the included studies (See Table 2). The quality of each study was rated using the following scoring algorithms: 8 to 10 stars were deemed as having good methodological quality, 5 to 7 stars were deemed as having moderate methodological quality, and 1 to 4 stars were deemed as having poor methodological quality. To advance the legitimacy of this systematic review result, we only included studies with good and fair methodological quality.

\begin{tabular}{|l|l|}
\hline \multicolumn{1}{|c|}{ Search Terms } & \multicolumn{1}{c|}{ Search Strategy Per Database } \\
\hline $\begin{array}{l}\text { Prevalence } \\
\text { Mortality }\end{array}$ & $\begin{array}{l}\text { PubMed: Advanced Search: ((Prevalence) AND (Maternal Mortality)) AND (West } \\
\text { Africa) }\end{array}$ \\
Cochrane Library: Advanced Search: All Text= Prevalence AND Maternal Mortality \\
AND West Africa.
\end{tabular}

Table2: Methodological quality assessment scores for included studies using the Newcastle-Ottawa Scale (NOS)

\begin{tabular}{|c|c|c|c|c|c|c|c|c|}
\hline & \multicolumn{3}{|c|}{ Selection } & \multicolumn{3}{|c|}{ Comparability } & \multicolumn{2}{|c|}{ Outcome } \\
\hline Study & $\begin{array}{l}\text { Representativ } \\
\text { eness of the } \\
\text { Sample Size }\end{array}$ & $\begin{array}{l}\text { Sample } \\
\text { Size } \\
\text { Justificat } \\
\text { ion }\end{array}$ & $\begin{array}{l}\text { Non- } \\
\text { responde } \\
\text { nts }\end{array}$ & $\begin{array}{l}\text { Ascertain } \\
\text { ment of } \\
\text { the } \\
\text { exposure }\end{array}$ & $\begin{array}{l}\text { Comparab } \\
\text { ility of } \\
\text { Subjects } \\
\& \text { Control } \\
\text { of } \\
\text { Confoundi } \\
\text { ng factors }\end{array}$ & $\begin{array}{l}\text { Assessm } \\
\text { ent of } \\
\text { the } \\
\text { outcome }\end{array}$ & $\begin{array}{l}\text { Statisti } \\
\text { cal test }\end{array}$ & $\begin{array}{l}\text { QA } \\
\text { S }\end{array}$ \\
\hline $\begin{array}{l}\text { Lilungulu, A } \\
\text { et'al } 2020\end{array}$ & * & * & * & $* *$ & * & *** & * & $\begin{array}{l}9 \\
\text { star } \\
\text { s }\end{array}$ \\
\hline $\begin{array}{l}\text { Fawole AO } \\
\text { et'al } 2012\end{array}$ & * & * & $*$ & $* *$ & $*$ & $* *$ & * & $\begin{array}{l}9 \\
\text { star } \\
\text { s }\end{array}$ \\
\hline $\begin{array}{l}\text { Hanson,C } \\
\text { et'al } 2015\end{array}$ & * & * & $*$ & $* *$ & $*$ & ** & * & $\begin{array}{l}9 \\
\text { star } \\
\text { s }\end{array}$ \\
\hline $\begin{array}{ll}\text { Høj, L et'al } \\
2002\end{array}$ & $*$ & $*$ & $*$ & $* *$ & $*$ & *** & $*$ & $\begin{array}{l}9 \\
\text { star } \\
\text { s } \\
\end{array}$ \\
\hline
\end{tabular}


Prevalence of Maternal Mortality in West Africa: A Systematic Review

\begin{tabular}{|c|c|c|c|c|c|c|c|c|}
\hline $\begin{array}{l}\text { Ntoimo, L.F } \\
\text { et'al } 2018\end{array}$ & $*$ & $*$ & $*$ & $* *$ & $*$ & ** & $*$ & $\begin{array}{l}9 \\
\text { star } \\
\text { s }\end{array}$ \\
\hline $\begin{array}{l}\text { Kaye, D. et'al } \\
2003\end{array}$ & $*$ & $*$ & $*$ & $* *$ & $*$ & $*$ & $*$ & $\begin{array}{l}8 \\
\text { star } \\
\text { s }\end{array}$ \\
\hline $\begin{array}{l}\text { Lancaster } \\
\text { B.S.L et'al } \\
2020\end{array}$ & $*$ & $*$ & $*$ & $* *$ & $*$ & $* *$ & & $\begin{array}{l}8 \\
\text { star } \\
\mathrm{s}\end{array}$ \\
\hline $\begin{array}{l}\text { Weyesa,J.B } \\
\text { et'al } 2015\end{array}$ & $*$ & $*$ & $*$ & $* *$ & $*$ & $*$ & $*$ & $\begin{array}{l}8 \\
\text { star } \\
\text { s }\end{array}$ \\
\hline $\begin{array}{l}\text { Lori, J.R. } \\
\text { et'al } 2010\end{array}$ & $*$ & $*$ & & $* *$ & $*$ & $* *$ & $*$ & $\begin{array}{l}8 \\
\text { star } \\
\text { s }\end{array}$ \\
\hline $\begin{array}{l}\text { Nansubuga,C } \\
\text {.et'al } 2016\end{array}$ & $*$ & $*$ & $*$ & $* *$ & $*$ & $*$ & $*$ & $\begin{array}{l}8 \\
\text { star } \\
\text { S }\end{array}$ \\
\hline $\begin{array}{l}\text { Airede, L.R. } \\
\text { et'al } 2009\end{array}$ & $*$ & $*$ & & $* *$ & $*$ & $*$ & $*$ & $\begin{array}{l}7 \\
\text { star } \\
\text { s }\end{array}$ \\
\hline $\begin{array}{l}\text { Moseson, } \\
\text { H.et'al } 2014\end{array}$ & $*$ & $*$ & $*$ & $* *$ & $*$ & & $*$ & $\begin{array}{l}7 \\
\text { star } \\
\text { s }\end{array}$ \\
\hline $\begin{array}{l}\text { Udjo, E.O. } \\
\text { et'al } 2013\end{array}$ & $*$ & $*$ & & $* *$ & $*$ & $* *$ & & $\begin{array}{l}7 \\
\text { star } \\
\text { s }\end{array}$ \\
\hline
\end{tabular}

QAS: Quality Assessment Score

Table3: Characteristics of included studies

\begin{tabular}{|c|c|c|c|c|c|c|c|c|}
\hline Author & $\begin{array}{l}\text { Study } \\
\text { Design } \\
\end{array}$ & $\begin{array}{l}\text { Study } \\
\text { Setting } \\
\end{array}$ & $\begin{array}{l}\text { Sample } \\
\text { Size } \\
\end{array}$ & Cases & $\begin{array}{l}\text { Setting/ } \\
\text { MDC }\end{array}$ & Prevalence & MMR & QAS \\
\hline $\begin{array}{l}\text { L. O. Omo- } \\
\text { Aghoja et'al } \\
2010\end{array}$ & $\begin{array}{l}\text { Cross- } \\
\text { sectional }\end{array}$ & Nigeria & 3,681 & 87 & HMR & $2.36 \%$ & 2,356 & Good \\
\hline $\begin{array}{l}\text { Fawole AO } \\
\text { et'al } 2012\end{array}$ & $\begin{array}{l}\text { Cross- } \\
\text { sectional }\end{array}$ & Nigeria & 9,208 & 79 & HMR & $0.86 \%$ & 927 & Good \\
\hline $\begin{array}{l}\text { C. F. L. } \\
\text { Hoestermann } \\
\text { et'al } 1996\end{array}$ & $\begin{array}{l}\text { Cross- } \\
\text { sectional }\end{array}$ & Gambia & 11,327 & 78 & HMR & $0.69 \%$ & 736 & Good \\
\hline $\begin{array}{l}\text { Høj, L et'al } \\
2002\end{array}$ & $\begin{array}{l}\text { Cross- } \\
\text { sectional }\end{array}$ & $\begin{array}{l}\text { Guinea } \\
\text { Bissau }\end{array}$ & 10,931 & 85 & SQ & $0.08 \%$ & 778 & Good \\
\hline $\begin{array}{l}\text { Ntoimo, L.F } \\
\text { et'al } 2018\end{array}$ & $\begin{array}{l}\text { Cross- } \\
\text { sectional }\end{array}$ & Nigeria & 5,262 & 91 & HMR & $1.72 \%$ & 2,085 & Good \\
\hline $\begin{array}{l}\text { Ndou, C et'al } \\
2013\end{array}$ & $\begin{array}{l}\text { Cross- } \\
\text { sectional }\end{array}$ & $\begin{array}{l}\text { Senegal } \\
\& \text { Mali }\end{array}$ & 89,518 & 593 & HMR & $0.66 \%$ & & Good \\
\hline $\begin{array}{l}\text { Meh, C et'al } \\
2019\end{array}$ & $\begin{array}{l}\text { Cross- } \\
\text { sectional }\end{array}$ & Nigeria & 51,492 & 1,561 & DHS & $3.03 \%$ & 1,121 & Good \\
\hline $\begin{array}{l}\text { Walraven, G } \\
\text { et'al } 2000\end{array}$ & $\begin{array}{l}\text { Cross- } \\
\text { sectional }\end{array}$ & Gambia & 16,116 & 74 & DHS & $0.51 \%$ & 424 & Good \\
\hline $\begin{array}{l}\text { Lori, J.R. } \\
\text { et'al } 2010\end{array}$ & $\begin{array}{l}\text { Cross- } \\
\text { sectional }\end{array}$ & Liberia & 148 & 28 & Interview & $20 \%$ & 2,020 & Good \\
\hline $\begin{array}{l}\text { Asamoah, } \\
\text { B.O. et'al } \\
2011\end{array}$ & $\begin{array}{l}\text { Cross- } \\
\text { sectional }\end{array}$ & Ghana & 226,209 & 605 & DHS & $0.27 \%$ & & Good \\
\hline $\begin{array}{l}\text { Airede, L.R. } \\
\text { et'al } 2009\end{array}$ & $\begin{array}{l}\text { Cross- } \\
\text { sectional }\end{array}$ & Nigeria & 9,158 & 197 & DHS & $2.15 \%$ & 4863 & Good \\
\hline $\begin{array}{l}\text { Moseson, } \\
\text { H.et'al } 2014\end{array}$ & $\begin{array}{l}\text { Cross- } \\
\text { sectional }\end{array}$ & Liberia & 1,985 & 71 & DHS & $3.57 \%$ & 890 & Good \\
\hline $\begin{array}{ll}\text { Zamané, } & \text { H } \\
\text { et'al } 2018 & \end{array}$ & $\begin{array}{l}\text { Cross- } \\
\text { sectional }\end{array}$ & $\begin{array}{l}\text { Burkina } \\
\text { Faso }\end{array}$ & 2,767 & 141 & HMR & $5.10 \%$ & 5,369 & Good \\
\hline
\end{tabular}

QAS: Quality assessment score; MMR: Maternal Mortality Ratio; HMR: Hospital Medical Records; SQ: Structured Questionnaire; PBS: Population Base Survey 


\subsection{Prevalence of the Maternal Mortality}

The prevalence of maternal mortality in Western Africa is $2.08 \%$ with a $95 \%$ confidence interval (CI) of $(0.85 \%, 3.83 \%)$, but the heterogeneity was substantially high $\left(\mathrm{I}^{2}=100 \%, \mathrm{p}<0.001\right)$. The forest plot in the Figure below shows the results.

\section{Study}

Asamoah BO et'al 2011

Ndou C et'al 2013

Meh C et'al 2019

Walraven $\mathrm{G}$ et'al 2000

Hoestermann CFL et'al 1996

Høj L et'al 2002

Fawole AO et'al 2012

Airede LR et'al 2009

Ntoimo LF et'al 2018

Omo-Aghoja LO et'al 2010

Zamané H et'al 2018

Moseson H et'al 2014

Lori JR et'al 2010

\section{Random effects mode}

Heterogeneity: $I^{2}=100 \%, \tau^{2}=0.0028, \chi_{12}^{2}=3327.90(p=0)$

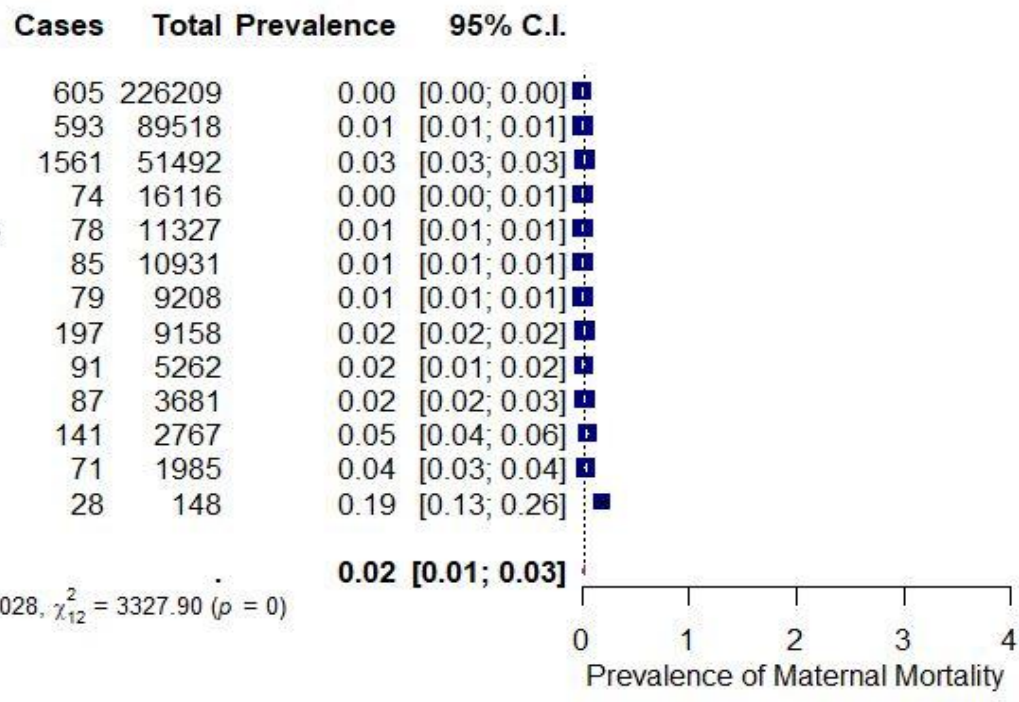

Figure2. Prevalence of Maternal Mortality in West Africa

Study setting and method of data collection were used to explore sources of heterogeneity. The following results were obtained.

\subsection{Study Setting}

With reference to study setting, the prevalence of maternal mortality is $1 \%$ for each of the following countries, with $95 \% \mathrm{CI}$ of $[0.00,0.3]$, $[0.00,0.05]$, and $[0.00,0.05]$, respectively:
Gambia; Guinea Bissau; and Senegal and Mali. Nevertheless, Ghana has the least prevalence of maternal mortality, whereas Nigeria, Liberia, and Burkina Faso, have [2\%, $(0.01,0.04)]$, [9\%, $(0.04,0.16)], \quad$ and $[5 \%,(0.01,0.13)]$, respectively, representing slightly higher prevalence of maternal mortality than their counterparts. The Figure below shows the details.

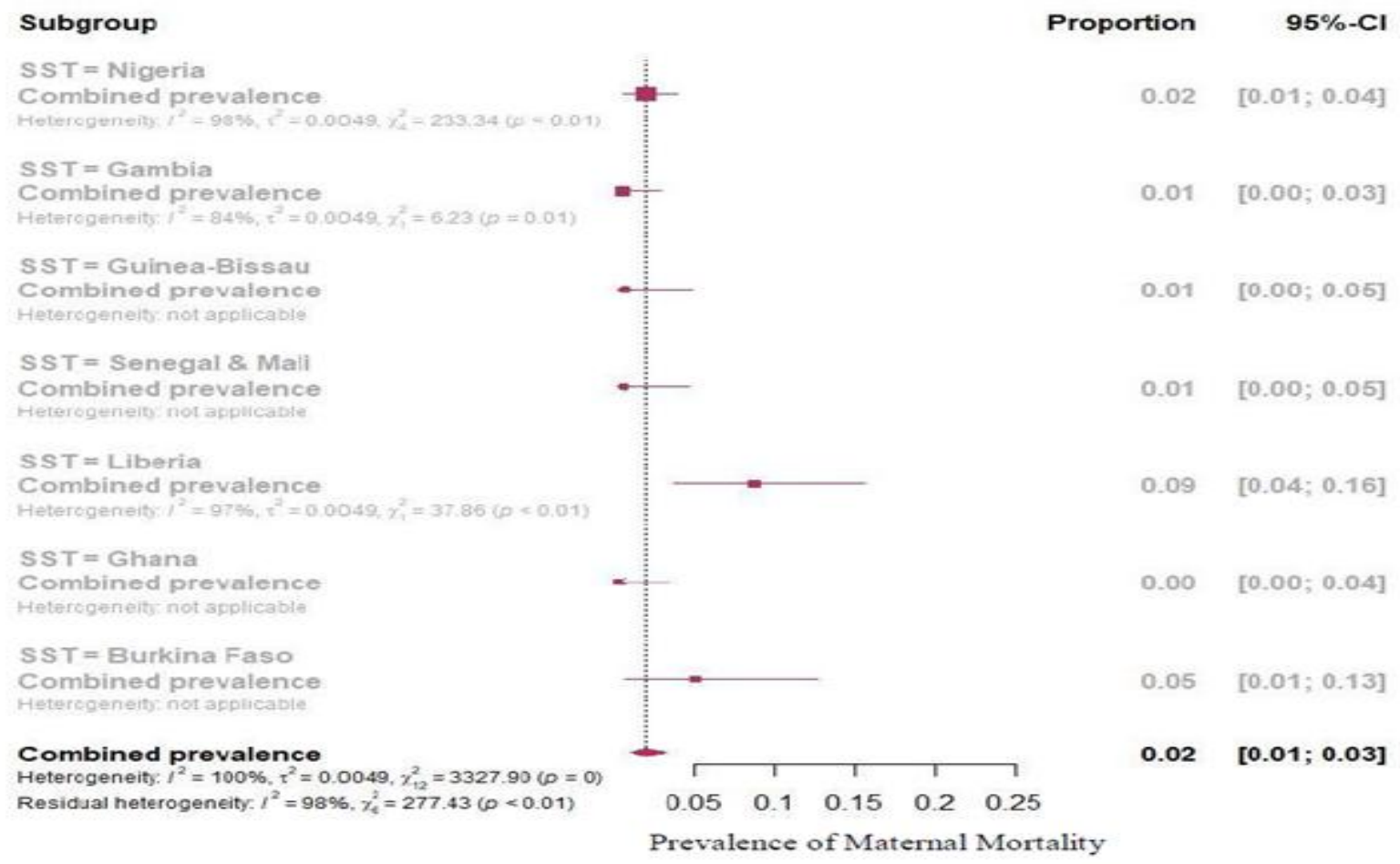

Figure3. Study setting 


\subsection{Data Collection Method}

Considering data collection methods, maternal mortality prevalence was higher when hospital medical records [2\%, 95\% CI $(0.01,0.03)]$, population based survey [4\%, 95\%CI $(0.03$, $0.04)]$, and interview $[2 \%, 95 \% \mathrm{CI}(0.09,0.31)]$ were used for data collection. The Figure below shows the details.

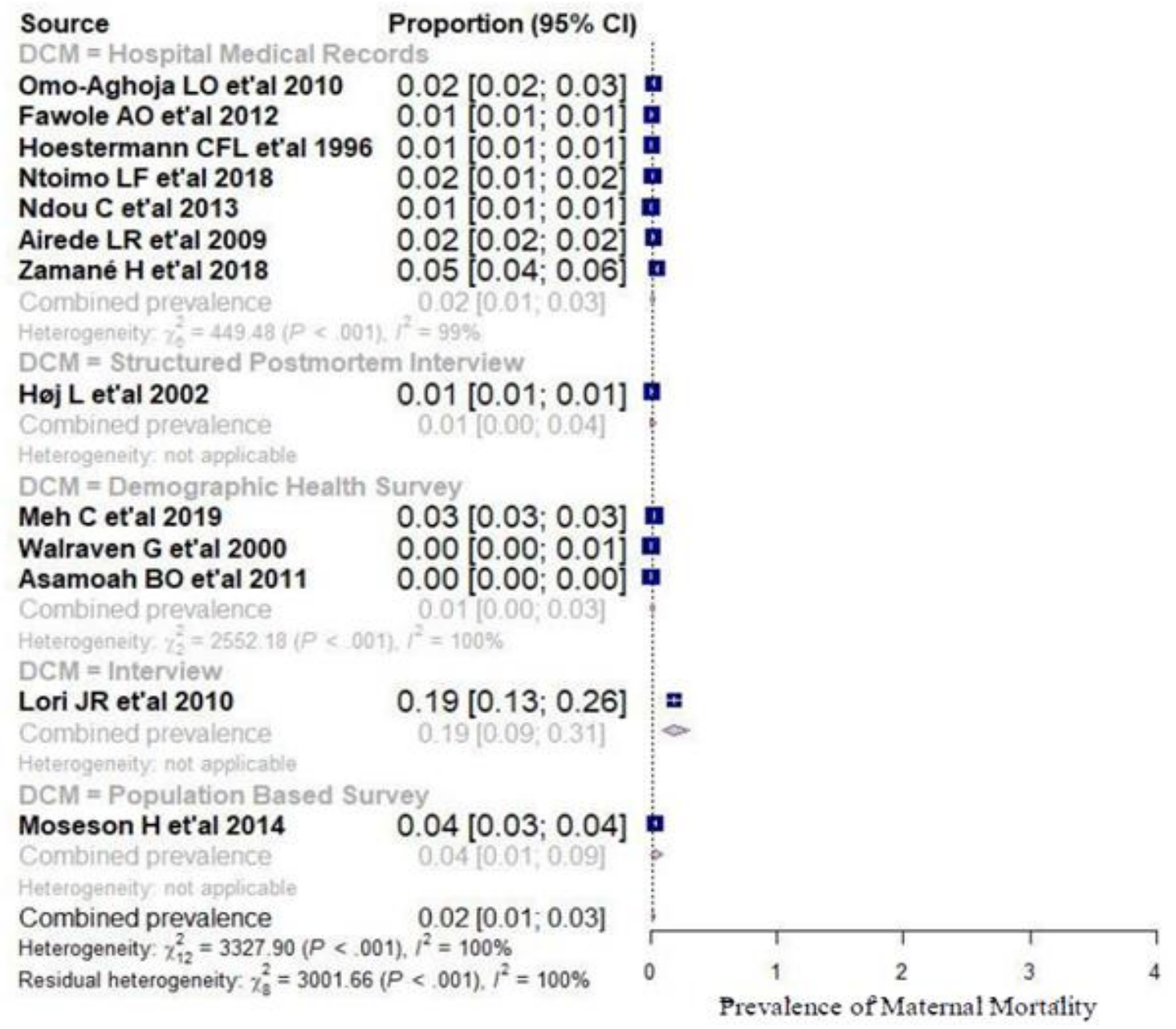

Figure4. Data collection

\section{DISCUSSION}

This systematic review assessed the prevalence of maternal mortality among reproductive-age women in West Africa and estimate a $2.08 \%$ overall prevalence rate. This review finding is in agreement with the widespread assumption that the prevalence of maternal mortality appears to be much lower in almost all regions of the world except in Africa. Despite the effort made in the health sectors of most Su-Saharan African countries to improve the quality of antenatal care, this study demonstrated deficiencies in major areas confronting maternal mortality. This study reveals a significant factor causing a rise in maternal mortality and major and how these challenges are been confronted in the various study settings.

Despite the drop in the prevalence rate of maternal mortality in West Africa as reported by this current review compared to past review findings, more efforts are still required to prevent and manage maternal mortality because our prevalence estimate exceeds $1 \%$, which is a cut-off score for declaring maternal mortality as a major public health problem [27]. The prevalence of maternal mortality in West Africa has not been so clear over the past few years. Several studies have tried estimating the prevalence and predictors of maternal mortality but their findings vary relatively from one country to another.

Several studies conducted in West Africa on maternal mortality estimated different prevalence rates for mortality among reproductive-age women such as 20\%[23], $5.10 \%$ [28], 3.57\%[29], and 2.36\%[30]. This variation in prevalence rate among studies is most likely associated with the factors of mortality.

This review provides invaluable insights into the 
magnitude of maternal mortality, the efficiency of maternal health services, and the quality of obstetric care in West African women in the period of 1990-2020. The review shows that HIV/ AIDS, eclampsia, puerperal sepsis, unsafe abortion, and postpartum hemorrhage, no antenatal care, low-level education, mode of delivery, were the leading cause of death [25, $30,31,32,33,34]$. Severe maternal morbidity (maternal near miss) is a distinct disorder that should be assessed in addition to maternal mortality [35,36]. Our review also identifies scarcity of data on mortality from specific obstetric complications such as case fatality ratios for the specific condition is impossible to estimate or compute. Upon al the wide variation in identification of cases, it was possible to pool data and make a summary estimate for maternal mortality to be $2 \%$, which is above the acceptable percentage of 1 . This is evident that the prevalence of maternal mortality is high which is an indication of poor quality care such as inadequate midwifery staff, blood, oxygen supplies, and low intensive care units [30]. Informing antenatal clients on pregnancy danger signs, and developing an emergency contingency plan, for women living in rural areas is important for decreasing geographical and financial barriers. [37,38]. The client's awareness of potential pregnancy danger signs is expected to decrease the amount of time between when a complication occurs, providers in most of our selected studies poorly in handling matters related to pregnancy danger signs, contributing immensely to a high level of prevalence of maternal death in most SubSaharan African countries. Similar results are documented for other parts of Tanzania and Sub-Saharan countries [39,40, 41,42, 43]

Our systematic review fulfills requirements in the consensus statement for reporting systematic reviews of observation studies [44] in presenting a systematic process of data collection and interpretation. Future studies should report on the specific causes of maternal mortality (complications that cause maternal death). Secondly, there is an urgent need to conduct longitudinal studies to assess the short-term and long-term impact of maternal mortality on the reproductive health of women as well as that of their families and communities. We accept this survey has a few qualities. Our search methodology was broad, comprehensive, and reproducible, as required by systematic reviews of published work. We did a thorough and straightforward methodological quality appraisal and endeavored to keep the bias of inclination due to methodological weakness to least by applying strict exclusion and inclusion criteria.

\section{CONClusion}

This systematic review summarizes the prevalence of maternal mortality among reproductive age women in West Africa. Our data highlight major prevalence and risk factors that could fluctuate the percentage level of maternal mortality in the next couples of years ahead and beyond. Our study reveals that there are large differences that exist between West African countries on the magnitude of maternal mortality in studies reported between 1990 and 2020. This could be due to different contexts/ settings and variations in criteria used to define the maternal mortality or rigor used carrying out the study.

This data also points toward specific interventions that could be further incorporated into healthcare systems or policies. Targeted, evidence-based interventions have the potential to vastly reduce the burden of preventable maternal mortality among women and in West Africa and around the world. Future studies in this area should incorporate precise definitions and risk estimates for mortality, including larger sample sizes, detailed statistical analysis and overlapping risk factors between these high-risk age groups.

\section{ACKNOWLEDGEMENTS}

The authors would like to thank their friends for their tireless gratitude and honest support while preparing this review.

\section{REFERENCES}

[1] WHO (World Health Organization): Health statistics and health information system. (2013), (Online), Index.html (Accessed 28 Feb 2013)

[2] Yenita A, Shigeko H.: Factors influencing the use of antenatal care in rural West Sumtraatra, Indonesia. Bio Med central. (2012); 12:9.

[3] World Health Organization. Maternal Mortality [Internet]. Factsheet. (2016)

[4] Hogan MC, et al: Maternal mortality for 181 countries, 1980-2008: a systematic analysis of progress towards millennium development goal 5. Lancet; (2010); 375(9726): 1609-1623

[5] WHO/UNICEF/UNFPA. Maternal Mortality in 2005: Estimates Developed by WHO, UNICEF, UNFPA and the World Bank. Geneva: WHO, 2007.

[6] Khan KS, Wojdyla D, Say L, Gulmezoglu AM, Van Look PF.: WHO analysis of causes of maternal death: a systematic review. Lancet 
(2006); 367: 1066-74.

[7] WHO, World Bank, UNICEF, United Nations Population Fund: Trends in maternal mortality: 1990 to 2008. Geneva: (2010).

[8] Ssengooba, F., Neema, S., Mbonye, A., Sentumbwe, O., \& Onama, V. Maternal health review Uganda: Health systems development Programme. Kampala: Makerere University Institute of Public Health \& DFID (2003).

[9] Alkema L, Chou D, Hogan D, Zhang S, Moller A-B, Gemmill A, et al. Global, regional, and national levels and trends in maternal mortality between 1990 and 2015, with scenario-based projections to 2030: a systematic analysis by the UN Maternal Mortality Estimation InterAgency Group. Lancet. (2016); 387(10017): $462 \pm 74$

[10] National Population Comission (NPC) Nigeria and ICF International. Nigeria Demographic and Health Survey 2013. Abuja, Nigeria and Rockville, Maryland; (2014).

[11] World Health Organization. Reduction of maternal mortality. A Joint WHO/UNFPA/ UNICEF/World Bank Statement. Geneva: World Health Organization, (1999)

[12] Fathalla MF. Human rights aspects of safe motherhood. Best Pract Res Clin Obstet Gynaecol (2006); 20: 409 - 419.

[13] Boama V, Arulkumaran S. Safe childbirth: A rights-based approach. Int J Gynecol Obstet (2009); 106: 125 -127

[14] Okonofua FE, Abejide OR, Makanjuola RO. Maternal mortality in Ile-Ife, Nigeria: A study of risk factors. Stud. Family Plann. (1992) 23(5):319-324. Olusanya

[15] World Health Organization. Trends in maternal mortality: 1990 - 2008. Estimates developed by WHO, UNICEF, UNFPA and The World Bank. Geneva: World Health Organization, (2010).

[16] Villar J, Carroli G. Gap between evidence and practice. Int J Gynecol Obstet (2001); 75 (Suppl 1): S47 - S54

[17] Sambo LG. Maternal mortality in the developing world - and the special challenge in Africa. In ATextbook of Postpartum Haemorrhage. Edited by B-Lynch C, Keith LG, Lalonde AB, Karoshi M, Dumfries hire: Sapiens Publishing, (2006): xxvii.

[18] Lewis G, editor. Why mothers die (2000 2002) - The Sixth Report of Confidential Enquiries into maternal deaths in the United Kingdom. London: CEMACH; (2004)

[19] Hogan MC, Foreman KJ, Naghavi M, Ahn SY, Wang M, Makela SM, Lopez AD, Lozano R, Murray CJ: Maternal mortality for 181 countries, 1980-2008: a systematic analysis of progress towards Millennium Development Goal 5. The Lancet (2010), 375(9726): 16091623.
[20] Thonneau PF, Matsudai T, Alihonou E, De Souza J, Faye O, Moreau JC, Djanhan Y, Welffens-Ekra C, Goyaux N: Distribution of causes of maternal mortality during delivery and post-partum: results of an African multicenter hospital-based study. European Journal of Obstetrics Gynecology and Reproductive Biology (2004), 114(2): 150-154.

[21] Rwandan Ministry of Health, Rwandan Ministry of Health, National Institute of Statistics of Rwanda, and ICF International: Rwanda interim demographic and health survey 2007-08. Calverton, Maryland, U.S.A: MOH, NISR, and ICF Macro; (2009).

[22] Airede, L. R. Ekele, B. A.: Adolescent maternal mortality in Sokoto, Nigeria; (2003); 23(2) 163165

[23] Lori, Jody R. Starke, Amy E. A critical analysis of maternal morbidity and mortality in Liberia, West Africa: (2012); 28 (1): 67-72

[24] Asamoah, Benedict O. Moussa, Kontie M. Stafström, Martin Musinguzi, Geofrey. Distribution of causes of maternal mortality among different socio-demographic groups in Ghana; A descriptive study: (2011); 11

[25] Høj, L. Da Silva, D. Hedegaard, K. Sandström, A. Aaby, P.: Factors associated with maternal mortality in rural Guinea-Bissau. A longitudinal population-based study; (2002); 109970; 792-799

[26] The Newcastle-Ottawa Scale (NOS) for Assessing the Quality of Nonrandomized Studies in Meta-Analyses (2018).

[27] FAO I U, WFP and WHO.: The State of Food Security and Nutrition in the World 2018. Building climate resilience for food security and nutrition. Rome, FAO. 2018.

[28] Zamané, Hyacinthe Sow, Hyacinthe Euvrard Kain, Dantola Paul Bicaba, Brice Wilfried Kiemtoré, Sibraogo Yameogo, Issaka BonanéThieba, Blandine Sawadogo, Mamadou: Maternal Mortality at the Dori Regional Hospital in Northern Burkina Faso, 2014-2016; 2019; 7(2); 235-241.

[29] Moseson, Heidi Massaquoi, Moses Bawo, Luke Birch, Linda Dahn, Bernice Zolia, Yah Barreix, Maria Gerdts, Caitlin: Estimation of maternal and neonatal mortality at the subnational level in Liberia; (2014); 127(2); 194-200

[30] Omo-Aghoja, L. O. Aisien, O. A. Akuse, J. T. Okonofua, F. E.: Maternal mortality and emergency obstetric care in Benin City Southsouth Nigeria; (2010); 5(3); 164-170.

[31] Fawole, A. O. Shah, A. Fabanwo, A. O. Adegbola, O. Adewunmi, A. A. Eniayewun, A. B. Dara, K. El-Ladan, A. M. Umezulike, A. C. Alu, F. E. Adebayo, A. A. Obaitan, F. O. Onala, O. E. Usman, Y. Sullayman, A. O. Kailani, S. Sa'id, M.: Predictors of maternal mortality in institutional deliveries in Nigeria; 
(2012); 12(1); 32-40.

[32] Hoestermann, C. F.L. Ogbaselassie, G. Wacker, J. Bastert, G.: Maternal mortality in the main referral hospital in The Gambia, West Africa; (1997); 1(5); 710-717.

[33] Ntoimo, Lorretta F. Okonofua, Friday E. Ogu, Rosemary N. Galadanci, Hadiza S. Gana, Mohammed Okike, Ola N. Agholor, Kingsley N. Abdus-Salam, Rukiyat A. Durodola, Adetoye Abe, Eghe Randawa, Abdullahi J.: Prevalence and risk factors for maternal mortality in referral hospitals in Nigeria: A multicenter study; (2018); 10(1); 69-76

[34] Ndour, Cheikh Dossou Gbété, Simplice Bru, Noelle Abrahamowicz, Michal Fauconnier, Arnaud Traoré, Mamadou Diop, Aliou Fournier, Pierre Dumont, Alexandre: Predicting In-Hospital Maternal Mortality in Senegal and Mali; (2013); 8(5)

[35] Souza JP, Cecatti JG, Parpinelli MA, Krupa F, Osis MJ: An emerging "maternal near-miss syndrome": narratives of women who almost died during pregnancy and childbirth. (2009); 36(2): 149-158.

[36] Stones W, Lim W, Al-Azzawi F, et al: An investigation of maternal morbidity with identification of life threatening "near miss" episodes. Health Trends (1991); 23(1): 13-15.

[37] Nikiema B, Beninguisse G, Haggerty JL: Providing information on pregnancy complications during antenatal visits: unmet educational needs in sub-Saharan Africa. Health Policy Plan (2009); 24:367-76
[38] Jahn A, Dar Iang M, Shah U, Diesfeld HJ: Maternity care in rural Nepal: a health service analysis. Trop Med Int Health (2000); 5:657-6

[39] NBS: Tanzania Demographic and Health Survey 2004/5.Dares Salaam, Tanzania: National Bureau of Statistics (NBS) and ORC Macro; 200

[40] Nikiema B, Beninguisse G, Haggerty JL: Providing information on pregnancy complications during antenatal visits: unmet educational needs in sub-Saharan Africa. Health Policy Plan (2009); 24:367-76

[41] Von Both C, Flessa S, Makuwani A, Mpembeni R, Jahn A: How much time do health services spend on antenatal care? Implications for the introduction of the focused antenatal care model in Tanzania. (2006); 6:22.

[42] Boller C, Wyss K, Mtasiwa D, Tanner M: Quality and comparison of antenatal care in public and private providers in the United Republic of Tanzania. Bull World Health Organ (2003); 81:116-22

[43] Improving maternal Mortality and Morbidity. Institute of medicine (US) Committee Birth Outcomes; Bale JR, Stoll BJ, Lucas AO, Editors Washington (DC). National Academics press, (2003)

[44] Stroup DF, Berlin JA, Morton SC, Olkin I, Williamson GD, Rennie D, et al: Meta-analysis of observational studies in epidemiology. A proposal for reporting. (2000); 283(15): 20082012

Citation: Kermue Vasco Jarnda, Garmai Prosperity Roberts, Williams Olokoro. Prevalence of Maternal Mortality in West Africa: A Systematic Review. ARC Journal of Gynecology and Obstetrics. 2021; 6(1): 10-20. DOI: doi.Org/ 10.20431/2456-0561.0601002.

Copyright: (c) 2021 Authors. This is an open-access article distributed under the terms of the Creative Commons Attribution License, which permits unrestricted use, distribution, and reproduction in any medium, provided the original author and source are credited. 